\title{
La ambigüedad de lo trágico: reflexión de la incidencia política, económica y social del cine en Colombia
}

Alejandro Jiménez

Pontificia Universidad Javeriana de Cali (Colombia) 



\title{
La ambigüedad de lo trágico: reflexión de la incidencia política, económica y social del cine en Colombia
}

\section{The ambiguity of the tragic: reflection on the political, economic and social impact of cinema in Colombia: a critical look}

\author{
Alejandro Jiménez \\ Pontificia Universidad Javeriana de Cali (Colombia) \\ jalejandro@javerianacali.edu.co
}

Fecha de recepción: 03 de septiembre de 2018

Fecha de aceptación: 28 de mayo de 2020

\begin{abstract}
Resumen
Una de las mayores dificultades que sufren los historiadores del cine (latinoamericano y colombiano en particular) es la falta de fuentes de información confiables, y la escasez de material histórico concluyente. En tal sentido, el presente documento se dirige a ampliar las indagaciones documentales sobre el fenómeno fílmico colombiano, por medio del análisis de la relación dialéctica entre el contexto nacional y las investigaciones históricas, estéticas y narrativas, consolidadas en proyectos cinematográficos nacionales y latinoamericanos; en este sentido, el objetivo fundamental es el reconocer de manera reflexiva la incidencia histórica, social, política y económica en el cine colombiano y su representación del entorno, concluyendo que el arte en general y el cine especialmente ha intentado reflexionar sobre las vicisitudes sociales y tal intención ha sido influida por factores externos como las condiciones económicas transnacionales o intereses desligados al quehacer cultural.
\end{abstract}

Palabras clave: Colombia; Latinoamérica; Cine; Representación; Historia de Colombia

\footnotetext{
Abstract

One of the greatest difficulties experienced by film historians (Latin American and Colombian in particular) is the lack of reliable sources of information and the shortage of conclusive historical material. In this regard, this document, through an
} 
La ambigüedad de lo trágico - A. Jiménez

extensive literature review, aims to expand documentary research on the Colombian film phenomenon, through the analysis of the dialectical relationship between the national context and historical, aesthetic and narrative research, consolidated in national and Latin American film projects; In this sense, the fundamental objective is to reflectively recognize the historical, social, political and economic impact on Colombian cinema and its representation of the environment.

Keywords: Colombia; Latin America; Cinema; Representation; History of Colombia

\section{INTRODUGGIÓN}

Partiendo de la idea de Álvaro Concha quien dice que "La historia del cine no se pude explicar por sí misma, sino a través de la Historia Social, donde se origina o se exhibe el producto cinematográfico" (Concha, 2014. p. 17) de igual forma, este devenir histórico ayuda a comprender y revelar condiciones de la cinematografía actual y por supuesto, contribuye a discernir los avatares de la sociedad. Gracias a que cada país vive su propio proceso de transculturación y establece una vaga conciencia de la naturaleza hibrida de sus formaciones culturales, se permite intuir sucesos tanto en la esfera del cinematógrafo como en los entornos políticos, económicos y sociales, lo cual reconoce la intertextualidad que plantea los contextos históricos, sociológicos y económicos frente a la reflexividad critica que desde el cine colombiano se ejerce sobre la realidad nacional, el cual reflexiona sobre nociones de identidad en el complejo universo del entorno social colombiano; igualmente es importante reconocer como plantea Del Valle (2016. P.7) que: "el cine es uno de los principales medios artísticos y culturales de los siglos XX y XXI, que lo han convertido en una fuente primordial de gran interés en el estudio de los desarrollos tanto en el ámbito político como en el imaginario colectivo de comunidades determinadas en periodos históricos específicos", así, estos periodos históricos constituidos en el imaginario colectivo provocan interés de los investigadores de los entornos sociales, que ayudan a comprender el papel que desempeña el cine en la representación del pasado.

Así mismo, esta exploración revela la dificultad que han tenido los historiadores con datos basados en la anécdota, en el recorte de periódicos, en boletines y acontecimientos de engorrosa comprobación, comprobando que el proceso histórico del cine colombiano no ha estado exento de mitologías. Como proceso cultural se hace necesario contribuir a saciar el vacío en torno a la realidad de la historiografía del cinematógrafo en Colombia y reconocer el creciente interés que plantea desde las ciencias sociales, la comprensión de los procesos culturales. De la misma forma, es interesante observar cómo algunos de los principales investigadores de la relación entre cine e historia como Sorlin, Lagni y Rosenton, involucran como aspecto fundamental del análisis del filme, la determinación de las condiciones políticas y económicas de producción, indispensables para su interpretación. (ibíd.). Finalmente, es posible 
concluir que es necesario reconocer la reflexión crítica que el cine colombiano plantea sobre la noción de identidad, a través de la apropiación o representación de momentos sociopolíticos que han influenciado la perspectiva colectiva de los fenómenos sociales. Es por esto que el interés de la presente investigación es indagar sobre relación dialéctica entre la producción cinematográfica y la observación de fenómenos específicos de la conflictividad sociopolítica colombiana

\section{METODOLOGÍA}

La presente investigación es resultado del proyecto exploratorio: "Forma e ideología en el cine colombiano: Violencia, Narcotráfico, Éxodo e Identidad" que fue desarrollado en el marco de un proceso de investigación más amplio sobre el cine colombiano.

Ahora bien, en el presente documento se configura una historiografía esquemática que toma como partida los hitos históricos y/o puntos de quiebre estético y narrativo que han sucedido en el transcurso de la vida cinematográfica nacional. Para lo cual se realizó una amplia revisión bibliográfica, fundamentalmente relacionada con el cine colombiano de temáticas generalistas y libros de carácter político, económico, social y relacionados con temas de identidad y cultura, en los cuales se relacionaron autores e investigaciones que permitieran confrontar acontecimientos históricos con la representación del cine de ficción nacional, afectado por realidades económicas y sociales que deformaron la producción cinematográfica.

Así, se realizó una búsqueda bibliográfica teniendo en cuenta la época comprendida desde la llegada de recurso cinematográfico a Colombia hasta el 2003, antes de la creación e implantación de la Ley de Cine (Ley 814). Es relevante la limitada cantidad de documentos históricos disponibles, siendo distinguidos los Catálogos de Patrimonio Fílmico Colombiano, Cinembargo Colombia de la investigadora Juana Suarez y las reflexiones contra el olvido del cine latinoamericano expuesto en el Carrete Mágico de King \& Bello (1994); igualmente, fue necesario revisar gran cantidad de documentos sobre el entorno social, político y económico para comprender las condiciones del país y sus posibilidades de representación en la cinematografía nacional.

Las fuentes estudiadas hacen parte, en su mayoría, del compendio de autores nacionales que han hecho camino investigativo, pese al enorme reto que comprende el levantamiento de información, prevaleciendo para la presente investigación, los fenómenos cinematográficos y de producción ocurridos en, por y para el cine colombiano. De esta manera, la unidad de sentido que compone el proyecto son los filmes nacionales que se analiza desde la llegada del cinematógrafo al país, hasta la consolidación de la Ley 814 de 2003, mejor conocida como Ley de Cine. 


\section{RELACIÓN TEÓRICA}

\section{1. (Ley 814 de 2003) Ley de Cine}

... la gente de Macondo no sabía por dónde empezar a asombrarse [...] Se indignaron con las imágenes vivas que [...]proyectaba en el teatro con taquillas de bocas de león, porque un personaje muerto y sepultado en una película, y por cuya desgracias se derramaron lágrimas de aflicción, reapareció vivo y convertido en árabe en la película siguiente. El público [...] no pudo soportar aquella burla inaudita y rompió la silletería [...], de modo que optaron por no volver al cine, considerando que ya tenían bastante con sus propias penas para llorar por fingidas desventuras de seres imaginarios" (Márquez, 1982).

La cinematografía colombiana ha permanecido ligada a la historia general del cine, al estar presente en los primeros años de la llegada del cinematógrafo Lumière a América, registrándose entre los lugares que visitaron los pioneros de dicha compañía (Arboleda, $r \cdots r$ ). A partir de allí, en Colombia, al igual que en la mayoría de los países de Latinoamérica, el cine ha sido parte de la cotidianidad cultural y social, consolidando en el imaginario nacional representaciones del entorno político, social y económico, de igual forma reflejando las relaciones de poder ejercidas a través de imágenes hegemónicas por parte de otros países -fundamentalmente Estados Unidos-. Entre los diversos modelos de producción, Hollywood posee el valor hegemónico sobre la creación de imágenes en movimiento de altísimos presupuestos, los cuales modifican la aplicación tecnológica, los mecanismos e infraestructuras del cine a nivel mundial. Este mismo estándar promueve transformaciones que afectan el conjunto de la cinematografía global y tocan, como es lógico, la producción colombiana, la cual se hace susceptible a las transformaciones, desde lo tecnológico como también desde lo narrativo.

En este marco, es posible apreciar cómo ciertas temáticas adquieren predominio de exhibición, como las películas de "narcos", en detrimento de otras manifestaciones igualmente trascendentales, las cuales requieren espacios de exhibición y cobertura mediática, para presentar diversas realidades sociales representadas en la cinematografía nacional.

Sin embargo, durante los últimos años, el cine colombiano ha estado amparado bajo un complejo cúmulo de transformaciones, mediadas en parte por políticas públicas en torno a la cultura y a la cinematografía. Algunos rasgos de dichos procesos han sido: la percepción del mejoramiento en las condiciones económicas y sociales del país, aumento de público en las salas de exhibición, capacitación de personal técnico y artístico, Ley de cine, etc.; responsables del aumento de películas colombianas exhibidas y su valoración en taquilla. 
Ahora bien, el fortalecimiento de procedimientos de alto nivel, que impulsan el crecimiento de la industria cinematográfica, ha posibilitado el ingreso a la producción local de creadores que involucran el conjunto de recursos audiovisuales como ficción, animación, documental, ensayo, arte y video experimental, (y otras experiencias de pantalla expandida como: documental interactivo, videojuegos, video360, etcétera) presentes en el marco del audiovisual mundial. Por otra parte, "el deseo de crear, construir historias a través de los recursos audiovisuales en condiciones profesionales, estimulan la imaginación de muchos creadores, directores y productores, que investigan los medios adecuados para cada uno de sus procesos de representación" (Jiménez, 2010, p. 20).

En este sentido, la implementación en Colombia de la Ley general de cultura (Ley 397 de 1997), la creación del Ministerio de Cultura y finalmente la aprobación de la Ley de Cine (Ley 814 de 2003), ha establecido sinergias en la actividad cultural, de gran relevancia en la historia del cine nacional. "La aplicación de nuevos modelos de producción, la aparición del cine digital, el estímulo del capital privado, la presencia y continua ampliación sobre los incentivos y subvenciones en distintos ámbitos del quehacer cinematográfico, han permitido el crecimiento en el volumen de películas colombianas en los últimos años: pasando de la casi inactividad (22 películas en el decenio 1987-1997), a una dinámica de lento pero en continuo crecimiento (133 títulos en el período 2003 - 2013), y en espera de lograr un volumen estable de títulos en un futuro inmediato." (Jiménez, 2008, p. 104)

\subsection{El cine Político vs. el cine Escapista}

Para comprender las dinámicas de diferenciación entre América Latina con el entorno colombiano es importante realizar un paralelo de la historia del cine colombiano con el cine político que emergió en Latinoamérica. En este contraste se encuentran diferencias, similitudes y características relevantes que deben ser mencionadas.

Por un lado, es necesario tener en cuenta que la semana del Arte Moderno celebrada en Sao Pablo-Brasil, considerado como punto de partida del Modernismo Brasilero afectó profundamente la cultura y el arte de ese país y de toda América Latina, (Johnson \& Stam, 1995). En este movimiento confluían elementos de las vanguardias europeas que fueron asimilados y reconstruidos para la realidad brasileña, generando entre otros, el movimiento Antropófago, que sugiere que el único trato posible con el imperialismo cultural era a través del canibalismo creativo, el cual proponía que el reciclaje de las influencias extranjeras podría ser atravesado por el sarcasmo y la parodia. Durante dicha semana se encontraron escasas referencias al cine, que ya para la época presentaba una dominación de mercado por parte de Hollywood en todo el continente, condición que fue cambiando paulatinamente. 
De la misma forma, las aglutinantes y dinámicas capitales de Argentina, México y Brasil y sus experiencias cinematográficas, se replicaron en otros países de la región, tardando en llegar a lugares apartados de los entornos capitalinos, donde además de filmar y representar eventos de importancia social y política, como: marchas militares, simulacros de incendio, y desde luego, representaciones de las familias más prestantes e importantes de cada región (en Colombia no fue la excepción), se realizaban tímidas aproximaciones a la ficción con contenido social.

Es importante destacar, que al encontrar mayor rentabilidad y menor riesgo, los empresarios locales optaron por los mecanismos comerciales sobre los mecanismos de producción, reduciendo la opción cinematográfica solo a aspectos de distribución y exhibición de películas extranjeras, minimizando la apuesta por la producción local. "Esta tendencia hacia una infraestructura comercial más estable, sucede sobre todo en las ciudades principales[...]incluso en los casos donde existían sistemas desarrollados de exhibición, en los cuales los empresarios locales luchaban con las compañias extranjeras por el control de la distribución, la producción doméstica se vio progresivamente marginada." (King \& Bello, 1994. p. 84).

Por otro lado, las políticas culturales empezaron a marcar las pautas de las diversas cinematografías, la llegada de los gobiernos militares y sus oficinas de propaganda, limitaron las condiciones de representación, promoviendo películas insulsas, que unidas a la mediocridad de productoras dispuestas a aceptar dichas condiciones, generaron una gama de comedias de costumbres con alto grado de melodrama. Algunos países como Chile o Cuba intentaron, a través del apoyo estatal, establecer mecanismos para convertir el cine en industria prioritaria, construyendo estudios o importando tecnología de punta; aun así, los elevados costos y los bajos indicadores de consumo local, dieron al traste con la mayoría de los intentos de la región. Argentina y México lograron establecer el predominio sobre el mercado en lo que se refiere a cinematografías regionales.

$\mathrm{Y}$ es que, al igual que las películas musicales de los charros mexicanos, las chanchadas de los brasileros, sirvieron para mantener a flote una industria en crisis debido a los conflictos bélicos mundiales; estas películas conquistaron fundamentalmente a la clase trabajadora a través de historias populares, livianas, generando un nuevo auge en el consumo de cine nacional en Brasil y México. A mediados de los cincuenta, el impulso del cine brasilero estuvo amparado en el desarrollo industrial, como parte del modernismo cultural que se vivía en el momento; la construcción de Brasilia inicia en 1956 y se convierte oficialmente como la capital de Brasil en 1960, representando el entusiasmo y la pujanza propias de los procesos de modernización.

Este rápido desarrollo generó un endeudamiento que llevó a una posterior crisis económica, en la cual algunos realizadores como Nelson Pereira dos Santos y el fascinante Glauber Rocha asumieron modelos del Neorrealismo Italiano y de la 
Nueva Ola Francesa, en los cuales se considera la: "intersección del cine de autor con la conciencia social y la intervención de un lenguaje para el subdesarrollo, que incorpore en la ficción los rasgos estilísticos del documental. El rompimiento con el lenguaje del cine comercial abre la posibilidad de transformar la pobreza técnica en la invención de un estilo" (Johnson \& Stam, 1995. p. 105).

Se debe mencionar igualmente al grupo argentino Liberación, con Fernando "Pino" Solanas y Octavio Getino como integrantes, quienes realizan entre 1966 y 1968, la película "La hora de los hornos", un proyecto de cuatro horas y veinte minutos de duración que presenta una estructura en tres partes: "Neocolonialismo y violencia", "Un acto para la liberación" y la tercera parte llamada "Violencia y liberación". La estructura formal de ruptura de su cinta está basada en el fragmento, la cita, la interrupción para el debate y la discusión de los contenidos propuestos por parte de los espectadores (Amado, 2009).

De la misma manera, Solanas y Pino Getino realizan un documento escrito denominado "Hacia un tercer cine", el cual es una reflexión sobre el neocolonialismo cultural; en el que se precisa lo que consideran el primer cine o de industria (Hollywood), el segundo cine, como cine de autor (Cine de Expresión, Nueva Ola, Cinema Novo, entre otros), diferenciados del tercer cine, que se presenta como un conjunto de: "Alternativas reales que difieran de aquellas que ofrece el sistema, que son sólo posibles cumpliendo uno de dos condiciones: haciendo películas que el sistema no puede asimilar y que son ajenas a sus necesidades, o haciendo películas que directa y explícitamente ataquen el sistema" (Solanas \& Getino, 1970).

Ya en 1969, el realizador cubano Julio García Espinosa, en detrimento de la perfección técnica de Hollywood y Europa, escribe el ensayo titulado Por un cine imperfecto, en el cual propone: "una cultura artística auténticamente revolucionaria, enfatizando en la cultura popular y en la acción del espectador como coautor", apoyado en las luchas de la gente común como materia prima de un cine alternativo e "imperfecto" (Espinosa, 1976).

También, los realizadores del Nuevo Cine Latinoamericano intentaron crear un cine revolucionario, tomando como punto de partida, además de la introducción de un nuevo contenido y la transformación de las formas cinemáticas, la transformación de las condiciones subjetivas, la producción y su vinculación con el público desde la acción y participación como interés prioritario. "Actualmente y a pesar de los esfuerzos institucionales, el aislamiento y la incomunicación regional, características de las cinematografias latinoamericana, sumadas a la aplastante tradición historiográfica del cine, marcan la naturaleza epistemológica de los estudios regionales y dificultan la crítica cinematográfica. Esta condición no sólo afecta al terreno de la epistemología, sino también los terrenos de la lógica argumentativa (tan importante para el análisis de secuencias) y de la articulación entre la ética y la estética del cine" (Zavala, 2010. p. 42). 


\subsection{La construcción de una identidad latinoamericana}

La declaración del realizador de cine silente mexicano, Manuel de la Bandera, a principios del siglo XX, refleja una realidad permanente en la representación de los entornos latinoamericanos por parte de Hollywood, especialmente en países golpeados por realidades sociales complejas y fáciles de estereotipar en las cíclicas caricaturas racistas de las cinematografías norteamericana y europea. "He visto en el extranjero [...] peliculas que son llamadas mexicanas y en las cuales se nos presenta a los ojos del mundo como verdaderos salvajes. En Estados Unidos hay primordial interés en mostrar un México inculto, lleno de supuestas maldades y vicios, sin hacernos justicia, sin reparar en nuestras bondades y grandezas" (King \& Bello, 1994. p. 39).

Frente a este panorama, De la Bandera propone que: "Mi tarea será hacer que en el exterior se sepa, mediante la utilización de actores mexicanos, que en nuestro pais hay gente culta, que hay cosas dignas de atención, y que ese salvajismo, ese atraso que utilizan para describirnos en películas mentirosas, [...].Y tanto él, como otros, pretendieron infructuosamente, a través de melodramas sentimentales resaltar los valores nacionalistas" (King \& Bello, 1994. p. 39).

A pesar de los esfuerzos de los primeros años por generar producción propia, lo cierto es que frente al irrefrenable poder de las cinematografías italianas y norteamericanas, los pioneros mexicanos optaron por la seguridad de la distribución como negocio. Ante esta situación, algunos realizadores decidieron auspiciar proyectos con valores nacionalistas, en particular las literaturas patrias. Así, en los años 20, se adaptaron algunos clásicos de la literatura latinoamericana, en el que casos como "María", del colombiano Jorge Isaacs, se ha convertido en uno de los textos más representados en la cinematografía del continente. Se adaptaron obras de José María Vargas Vila, como "Aura o las violetas", algunas representaciones nacionalistas de las gestas libertarias, como "El Húsar de la Muerte", en Chile; e incluso luchas sociales como en Bolivia, donde se realizó "Corazón de Aymará", y "La profecía del lago", que representaban las luchas indigenistas de la época (King \& Bello, 1994.).

En medio de la exaltación nacionalista, llegaron gran cantidad de exiliados europeos huyendo de las guerras y los vientos fascistas que se agitaban por toda Europa, entre estos exiliados estaba Luis Buñuel. En sus inicios, el mismo Buñuel reconoce que decía a sus amigos sobre América Latina: "si desaparezco, buscadme en cualquier parte, menos alli" (Buñuel, 1982. p.192), Buñuel venía de decepcionantes experiencias en Hollywood y fue conquistado por una cultura viva, donde logro crear 32 películas en sus más de 30 años de vida en México, aportando enorme riqueza a la cultura mexicana y al cine latinoamericano en general (Buñuel, 1982).

De la misma manera, la revolución cubana configuró, con sus argumentos nacionalistas y antiimperialistas, gran parte del espíritu latinoamericano de la época, al integrar las vanguardias artísticas con las inclinaciones sociopolíticas; los 
escritores del llamado Boom latinoamericano, entre los que se encontraban Gabriel García Márquez, Carlos Fuentes, Julio Cortázar, etc., reflejaron la esencia de la época, dando entrada al postmodernismo en América Latina. El advenimiento de los fructíferos movimientos culturales de los años 60, estaba basado fundamentalmente en el resurgimiento económico de la región. La instauración de industrias permitía disminuir la importación de productos del exterior y mejorar las condiciones económicas locales, lo cual era apoyado por los Estados Unidos, a través de los lineamientos de la Alianza para el Progreso, con lo que pretendían fortalecer las naciones y al mismo tiempo rehuir del marxismo instaurado en Cuba.

También, la llegada de los años setenta en América latina estuvo marcada por aires revolucionarios, se establecieron manifiestos que buscaban rupturas con los mecanismos dominantes, propiciando un cine: "Lúcido, crítico, realista, popular, antiimperialista y revolucionario, y rompería las actitudes neocolonialistas y las prácticas monopólicas de las compañías norteamericanas. No promulgaría ninguna fórmula estética: la flexibilidad sería necesaria para adaptarse a las diferentes situaciones sociales" (King \& Bello 1994. p. 102). Dichos manifiestos, donde los cineastas fungían como teóricos, proclamaron, los llamados 'Nuevos Cines', donde se integraban la cultura, las tradiciones y la lucha revolucionaria; estimulando reflexiones para cambios sociales y políticos en los entornos locales y panamericanos.

Los cineastas encontraron espacios simbólicos en la cotidianidad, a través de mecanismos flexibles, de bajo presupuesto, con "una idea en la cabeza y una cámara en la mano", como afirmaría en repetidas ocasiones Glauber Rocha (Johnson \& Stam, 1995) y donde se ponían de manifiesto las relaciones entre los realizadores y el Estado; fundamentalmente los requerimientos de producción en condiciones de escasez y la construcción de mecanismos de distribución por fuera de los medios establecidos. Igualmente era prioritaria la búsqueda de lenguajes cinematográficos apropiados a las necesidades de la 'realidad nacional' que se pretendía representar.

A partir de los ochenta, los nuevos aires -marcados por la finalización de la mayoría de las dictaduras y el retorno de las democracias- no se vieron reflejados en la búsqueda de un lenguaje propio o una reflexión sobre la identidad. Las nuevas problemáticas se basaron en la búsqueda de recursos económicos para hacer películas que pudieran ser amortizadas en las salas de cine, reduciendo drásticamente las fuentes de financiación, inicialmente con la implementación de recursos estatales que apoyaban la realización cinematográfica, a través de políticas públicas. En el caso colombiano -con Focine- se improvisó y se despilfarró en gran medida, sin capitalizar las experiencias padecidas con anterioridad.

\subsection{Cine colombiano: entre el mito y la realidad (los primeros años)}

Los pasos iniciales del cine en Colombia y fundamentalmente su estudio historiográfico (al igual que la mayoría de los procesos culturales) se ha constituido 
en un enigma histórico, fundamentalmente debido a que la prensa y cronistas de la época, consideraban al cinematógrafo mera curiosidad de feria, al minimizar su aparición en las publicaciones impresas, dificultando así su seguimiento y comprobación histórica. En algún momento, historiadores venezolanos llegaron a afirmar que alguno de los camarógrafos itinerantes enviados por los Lumière habrían filmado en el Puerto de la Guaira (Venezuela), entre 1898 y 1899 (a escasos cinco años de la invención del cinematógrafo) y que por extensión debieron continuar por el mar Caribe llegando a los puertos de Cartagena, Santa Marta o Barranquilla, en Colombia; desafortunadamente esta información no ha tenido respaldo de ninguna fuente confiable y puede estar más motivada por el deseo que sobre la realidad (Silva, 1981).

El investigador Carlos Álvarez (Álvarez, 1981) destaca que la primera llegada de un aparato cinematográfico a Colombia fue en 1897, en la ciudad de Colón, cuando Panamá aún formaba parte del territorio colombiano. El mecanismo consistía en un Vitascopio de Edison, que venía de Centroamérica y terminaría remontando el río Magdalena hacia el interior del país; Duque complementa este hallazgo: "una máquina que lanzaban sobre el telón 45 imágenes por segundo[...] los espectadores miraban deslumbrados las vistas de caballos corriendo, carros eléctricos que subian y bajaban por las calles, personas andando, trenes en movimiento, el humo que salía de las chimeneas de las locomotoras y las olas del mar estrellándose contra las rocas" (Duque, 1992. p.25 ).

Gracias a la respectiva corroboración histórica, es posible afirmar, que la primera filmación realizada en Colombia se efectuó en 1899 en la ciudad de Cali, cuyo contenido se asume como un fragmento de un noticiero para ser incluido en otras notas extranjeras (Silva 1981), donde predominaban "vistas" del exótico paisaje colombiano, eventuales procesiones religiosas y actos oficiales.

Finalizando el siglo XIX, se desató la Guerra de los Mil Días (1899-1902), contienda civil que generó caos en la administración nacional y devastó la débil economía de un país naciente, afectando el transporte y exhibición de películas, dejando en lamentable estado las vías de comunicación, además de una deuda externa exorbitante; esta guerra dispuso las condiciones para el despojo por parte de los Estados Unidos del departamento de Panamá en 1903. Sobre este asalto norteamericano se realizó un filme llamado "Garras de oro", que fue censurado, prohibido y boicoteado por el Departamento de Estado norteamericano (Suarez, 2009).

En 1909, los hermanos italianos Di Domenico se establecieron en la ciudad de Bogotá, donde conformaron Di Domenico Hermanos y Cia, de la cual también participaban sus primos y otros socios, dedicando su actividad comercial a la importación y exhibición de películas. Fue tan próspero el negocio, que en 1912 inauguraron un suntuoso teatro llamado Salón Olimpya, con capacidad para 3.000 personas, en el cual exhibían obras italianas y francesas (Martínez Pardo, 1978). 
En 1915 esta poderosa distribuidora da inicio a la producción de "filmes con puesta en escena, pero con sentido más bien documental" (Isaza, 1992. p.55), grabando eventos sociales, cívicos y religiosos, como: "El drama del 15 de octubre", sobre el asesinato del General Rafael Uribe Uribe, en la que actuaban los verdaderos asesinos del jefe político-militar (Suarez, `. $_{9}$ ).

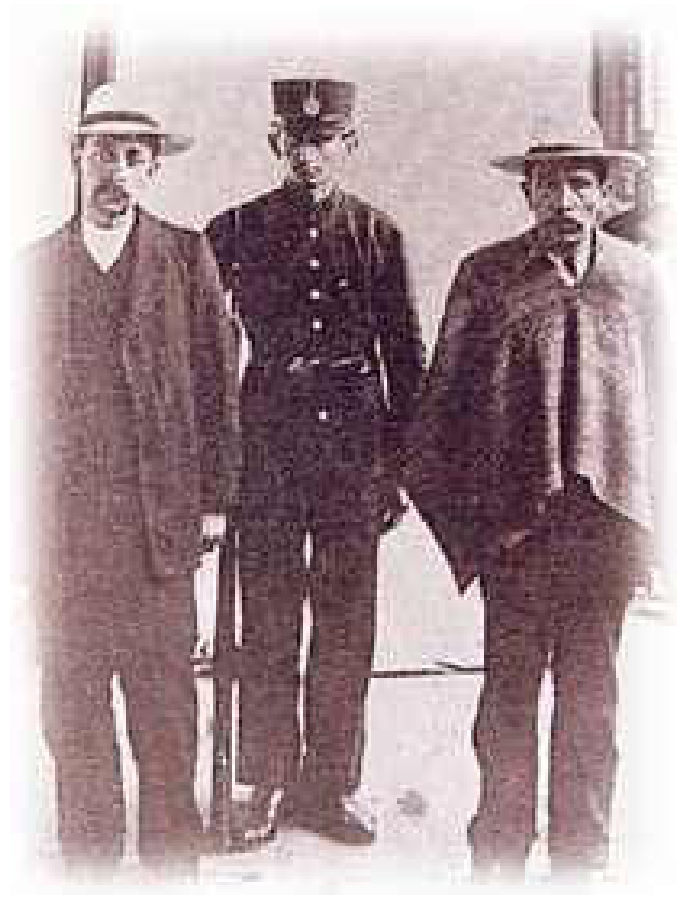

Imagen 1. El drama del 15 de Octubre. de Hermanos di Domenico. (1915).

Reproducción de un fotograma en 35 mm (Archivo Fundación Patrimonio Fílmico Colombiano)

Donato Di Domenico afirma haber realizado y exhibido el primer filme de ficción en Colombia, en 1921, llamado "Tierra caucana" (Silva, 1981), en la que realiza un acercamiento a la exótica y fértil tierra del sur de Colombia. Durante esa época, pasada la agonía de la guerra civil, se genera una relativa prosperidad económica, debido a la incontable migración europea posterior a la Primera Guerra Mundial y al desabastecimiento del continente europeo, que requería materias primas para su sobrevivencia y recuperación.

Así mismo, la obra "María" es considerado el primer largometraje argumental colombiano, basado en la novela homónima del escritor Jorge Isaacs, filmada entre 1921 y 1922 en la hacienda "El Paraíso" -lugar que ha servido de escenario natural a varias versiones de la misma novela-, y que corresponde al lugar donde transcurrieron los hechos descritos en el relato melodramático; esta película fue producida por el 
sacerdote Antonio J. Posada y dirigida por el actor español Alfredo del Diestro, quien también se encargó de la adaptación literaria. Edda Pilar Duque, en su libro "La aventura de cine de Medellín", afirma que: "Tras el éxito de María, siguieron otras filmaciones. En las principales ciudades del país se dieron los primeros brotes de una incipiente producción de largometrajes argumentales. Los cineastas vieron en las obras literarias y en los dramones sentimentales un excelente recurso para ampliar su radio de acción" (Duque, 1992. p.102). Además, los problemas con los intolerantes miembros de las juntas de censura quedaron superados, al no atreverse estos a cuestionar la calidad escritos por los literatos más prestigiosos de la época; de ahí la tendencia cada vez más acentuada hacia el filme costumbrista y moralizador (Duque 1992).

De la misma manera, los hermanos Di Domenico, con su productora Sicla rodaron varias películas, destacándose la adaptación de "Aura o las violetas" película que constituyó un gran éxito comercial en 1924. del escritor José María Vargas Vila, dirigida por el jefe del clan familiar: Vicente Di Domenico. En 1924. se realizaron dos filmes en Manizales, la primera fue "Madre" un melodrama moralista y posteriormente "Manizales city" un documental sobre la pujanza de la región, donde no faltó ningún benemérito miembro de la dignidad manizaleña.

El dramaturgo y ensayista Arturo Acevedo Vallarino, también entró a la historia del cine nacional con largometrajes como: "La tragedia del silencio" (1924), posteriormente, realiza una de las películas más reconocidas del período silente llamada: "Bajo cielo antioqueño", escrita y producida por Gonzalo Mejía, un respetado hombre de negocios de Medellín, quien aprovechando el melodrama de la relación imposible entre ricos y pobres y el triunfo del amor, saca a relucir una Antioquia pujante, rica en industria y en recursos naturales con una sociedad de estirpe y valores intachables.

Durante la segunda década de del siglo XX surgieron otros exhibidores en las grandes ciudades, construyendo teatros de uso exclusivo para la exhibición cinematográfica, teatros que cuentan con millares de anécdotas sobre el público que aplaudía luminosos atardeceres, vitoreaba las tonadas interpretadas por los músicos presentes, orquestas que en ocasiones cambiaban las partituras musicales enviadas por los estudios norteamericanos por melodías locales, indistintamente, ocurrían pérdidas de rollos de películas en el transporte entre los teatros, hasta incendios de palacios de exhibición al más puro estilo de Cinema Paradiso.

Posteriormente, la Gran Depresión norteamericana repercute críticamente en todas las latitudes, en 1927, las principales productoras nacionales cerraron sus estudios: la Colombia Film Company de Cali quebró, Di Domenico Hermanos habría vendido a la nueva empresa antioqueña Cine Colombia todos sus bienes. La empresa Acevedo e Hijos vio detenida la producción de noticieros causado por el cierre de los laboratorios de los Di Domenico. 


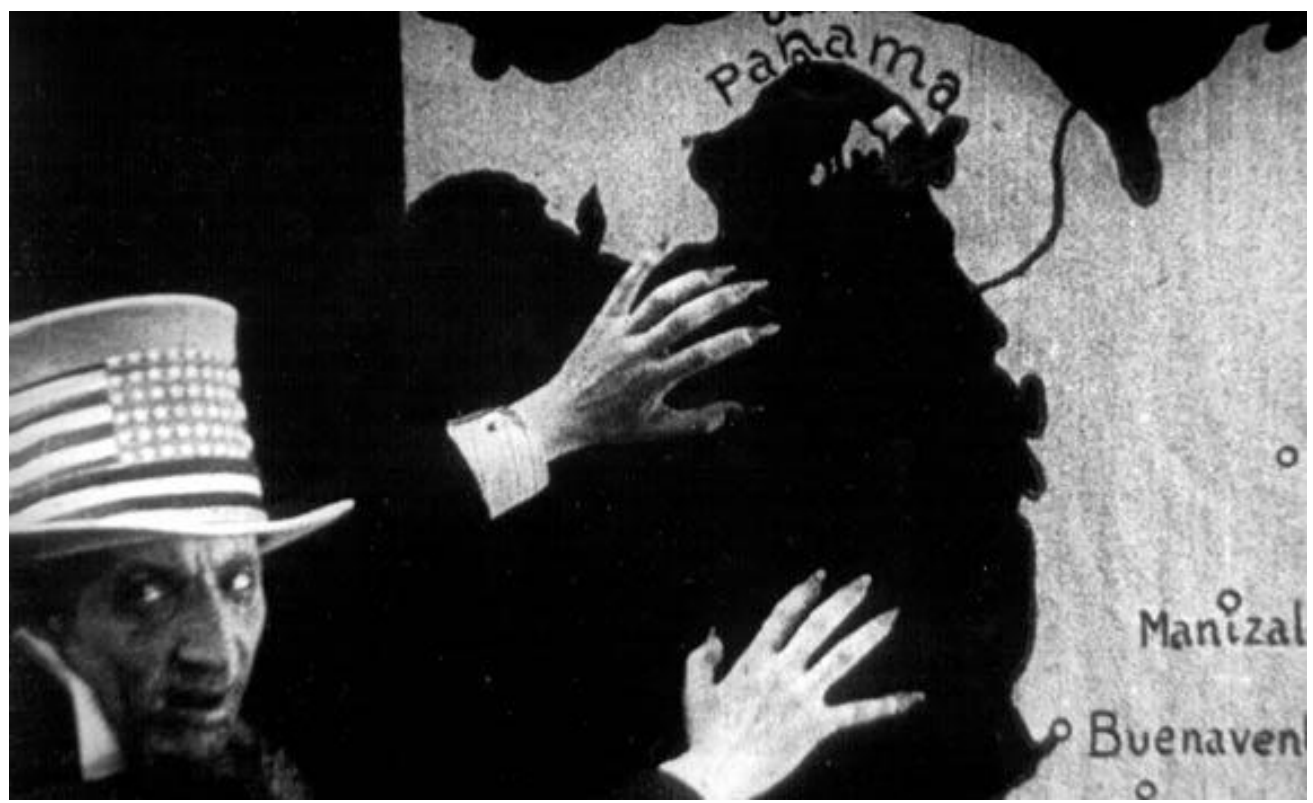

Imagen 2. Fotograma de la película Garras de Oro (1927), Reproducción de un fotograma en 35 mm (Archivo Fundación Patrimonio Fílmico Colombiano)

Así mismo, la aparición del sonido sincrónico en Estados Unidos transformó la totalidad del sistema y generó un sismo que arrastró a grandes y pequeños por igual (Mérida \& Blanco, 2002). Los estudios se transformaron por la necesidad de insonorizarlos, los actores se enfrentaron a sus problemas de voz, dicción e idiomas, los exhibidores debieron cambiar todo el sistema de las salas para adecuarlo a la reproducción del sonido, entre otros. Fue un reto gigantesco para todo el andamiaje del cine. La transformación de la técnica también cambió la temática y narrativa de las películas, en principio se prioriza la palabra hablada sobre la acción, esto agudizó más la dificultad para los públicos latinoamericanos y europeos para entender las palabras y las películas estadounidenses en general (Jiménez, 2010).

La empresa Cine Colombia sacó partido de esta nueva situación, vendiendo los nuevos proyectores a plazos a pequeños teatros y ciudades intermedias, con la exigencia de exhibir películas distribuidas exclusivamente por Cine Colombia (Isaza 1992). Estas prácticas monopolizadoras, sin regulación estatal, asociado al poco interés que han mantenido los distribuidores en la producción nacional, han sido uno de los principales causantes de la permanente agonía del cine colombiano. La frivolidad del Star System -que se posicionó definitivamente durante el decenio de los treinta al cuarenta- contrastaba con una población colombiana empobrecida por el cierre del flujo de capital extranjero debido la caída del precio del café y otros 
factores asociados a la Gran Depresión. Los ídolos del celuloide se convertían en ideales de vida y las salas se llenaban de jóvenes que soñaban en convertirse en Joan Crawford o Greta Garbo, sin salir de los rudimentarios modelos patriarcales y moralistas presentes en la sociedad colombiana.(Martínez Pardo, 1978)

Entre 1931 y 1937 y en palabras de Hernando Martínez Pardo, "De acuerdo con los estudios del cine nacional no hay registros de ninguna clase de corto o pelicula argumental producida durante este periodo." (Martínez, 1978, p.67). Igualmente, las familias adineradas compraron pequeñas cámaras filmadoras llamadas Pathé Baby, que por su fácil manejo, permitían inmortalizar los eventos cotidianos.

En 1937 surgen los primeros ensayos de cine parlante en Colombia, producido por la casa Acevedo e Hijos y Carlos Schroeder, quienes presentaron el documental "De la cuna al sepulcro", que consistía en "una recopilación de imágenes con motivo de la muerte del expresidente Olaya Herrera, con banda sonora compuesta especialmente para la cinta y que incluía discursos de diversos políticos de la época con sonido sincrónico directo" (Arboleda, 2003, p.89).

Durante la Segunda Guerra Mundial y a pesar de la dificultad para conseguir material virgen en medio de la guerra, Máximo Calvo realizó "Flores del Valle", el primer largometraje argumental sonoro colombiano, en tono melodramático, donde una mujer campesina logra sobreponerse a los prejuicios sociales con que la han humillado en la ciudad; a pesar de la buena acogida de la película, en su día de estreno fue boicoteada por algunos distribuidores y exhibidores que argumentaron compromisos con las distribuidoras mexicanas y norteamericanas (Silva, 1981).

Durante los años cuarenta, cuando se enmarcaron en extremismos políticos, los líderes invitaban a la violencia y al control territorial, igualmente la iglesia amenazaba con el fuego del infierno a quienes no siguieren los preceptos conservadores y las poblaciones eran destinadas a pertenecer a doctrinas que apenas entendían. El 9 de abril de 1948 fue asesinado el líder popular liberal y candidato a la presidencia de la república, Jorge Eliécer Gaitán, hecho que desató la ira de las masas populares y generó el llamado "Bogotazo", desatando una revuelta popular masiva, dando apertura a la época conocida como "La Violencia". que conllevo posteriormente al Golpe de Estado de 1953 a cargo del general Gustavo Rojas Pinilla, quien entregó el poder años después a una coalición de los partidos dominantes.

Estos arreglos realizados entre políticos y la burguesía en la distante Bogotá, sin la participación de las facciones realmente enfrentadas en los campos, solo aplazaron cuestiones sin resolver, dejando excluidos grupos políticos y sociales que no lograron la reconciliación; lo que estimuló la germinación de los grupos armados de izquierda, a quienes no se les permitieron espacios políticos.

Los años cincuenta estuvieron marcados por la represión y el miedo; las movilizaciones, la lucha por los derechos y la confrontación armada. La persecución estatal desde el gobierno conservador hacia los liberales, ateos y comunistas, 
siguiendo las directrices de la política internacional de la Guerra Fría, que se ordenaba desde los Estados Unidos hacia los países latinoamericanos. En este ambiente de represión era lógico que el cine también sufriera los rigores de la censura cada vez más sectaria. Se llegó a casos como el de establecer la Ley 83 de 1946, donde se consideraba al cine como uno de los factores influyentes de la delincuencia juvenil, prohibiéndole de esta forma a los menores de 5 años asistir a los teatros, y los chicos entre 5 y 16 años solo podrían acudir de día y exclusivamente a películas científicas o recreativas aprobadas previamente por la censura.

El Golpe de Estado acrecentó el régimen de represión estatal, se declararon zonas de guerra contra las guerrillas comunistas, se masacraron estudiantes durante las protestas civiles y se establecieron mecanismos de abuso autoritario. Las producciones cinematográficas se redujeron casi en su totalidad, dejando únicamente espacio para la realización de cortometrajes institucionales, publicidad, películas de turismo y el acompañamiento de los actos oficiales del gobierno.

En 1954 llega la televisión a Colombia de la mano del dictador Gustavo Rojas Pinilla, y rápidamente dicha tecnología invade los hogares colombianos, asestando otro duro golpe a la mínima producción de cine nacional, provocando que en 1956 desaparecieran la mayoría de las casas productoras de cine publicitario. Sin embargo, durante ese año se produce "La langosta azul", realizada a manera de experimento surrealista por un grupo de artistas e intelectuales de la época, entre ellos: Gabriel García Márquez, Álvaro Cepeda Zamudio, Luis Vincens y Enrique Grau. Hasta entonces el cine nacional había limitado sus temáticas a narraciones bucólicas, románticas y, en ocasiones históricas, que pocas veces tenía como base una reflexión sobre la realidad colombiana (Arboleda, 2003).

"La Nueva Ola se encrespaba en Francia, el Free Cinema descarrilaba las cámaras en Londres, Andy Warhol retrataba al Empire State durante 12 horas y lo mostraba en los sótanos de Nueva York, Hitchcok había pasado por "Psicosis" y "Los pájaros", el "Silencio" de Bergman rompía los vericuetos del alma y Glauber Rocha, Ruy Guerra y Nelson Pereira Dos Santos incendiaban el mundo desde Latinoamérica con sus enloquecidos movimientos de cámara y el estruendo de su denuncia social en el Cinema Novo." (Laguado, 2001, p.96). Estas influencias llegaron a Colombia de la mano de algunos jóvenes cineastas que intentaban dejar atrás el estereotipo del cine norteamericano y mexicano, buscando temáticas que se aproximaran a la realidad nacional, llevando al surgimiento de un cine marginal en todos los aspectos, desde sus pobres mecanismos de producción hasta las mínimas posibilidades de exhibición, un cine de didáctica política y un recurso de denuncia al establecimiento.

\subsection{La llegada a la contemporaneidad.}

La sociedad colombiana - pasando por tragedias heredadas y otras de nueva invención- ha pretendido una transformación cultural, basada en reconocer la 
complejidad del contexto, evitando el simplismo cinematográfico de buenos contra malos, vaqueros contra apaches; y con ello, restablecer miradas amplias sobre los conflictos, en los que la diversidad se interpreta como elemento fundamental para la construcción de la política y la cultura. Precisamente, estos referentes son representados en la cinematografía nacional contemporánea, donde los personajes no son lo suficientemente buenos ni suficientemente malos, subsumidos en la fangosa ética de la realidad nacional.

La producción fílmica colombiana -fundamentada económicamente en el consumo interno- ha promovido los medios y lenguajes disponibles en la creación fílmica de ficción, constituyendo un elemento del eje de representación, hace énfasis en la percepción de la realidad local. De esta forma, se han asumido nuevas estructura sociales de predominio urbano, en menoscabo de la vida rural, representada profusamente años atrás. Por otra parte, la renovación de los actores de la creación contemporánea en Colombia han obligado a una reflexión sobre la labor comprometida de los medios de expresión, independientes de los sistemas televisivos, tan predominante aun hoy día.

Durante los años setenta se dieron diversas miradas desde la producción cinematográfica, resaltando el documental como principal mecanismo de representación y reflexión. Personajes fundamentales como, Martha Rodríguez y Jorge Silva, crearon una serie de películas fundamentales para comprender el poder de la imagen y el compromiso ante las injusticias sociales. Rodríguez, se había formado como antropóloga y estudió cine al lado de Jean Rouch, luego se une al fotógrafo Jorge Silva para realizar, entre otras, la película "Chircales", rodada entre 1966 y 1972, tal vez el documental colombiano con mayor reconocimiento internacional (Suárez, 2009); con ella se acercan a la realidad que sufre una familia en la fabricación de ladrillos artesanales en una comunidad aledaña a Bogotá.

Igualmente, Carlos Álvarez, personaje de gran actividad, escribió crítica cinematográfica en periódicos y revistas, y fue implacable con muchos cineastas colombianos a quienes consideró escapistas y faltos de compromiso, entre ellos a: Guillermo Angulo, Jorge Pinto, Álvaro González y Francisco Norden, jóvenes de clases adineradas que regresaban de sus estudios en el exterior. Álvarez impulsó los cineclubes y resaltó el valor de la creación de cortometrajes y documentales desde la experiencia académica. Precisamente, su película "Asalto" (1968) ganó gran popularidad entre la audiencia universitaria al tratar sobre el allanamiento de la Universidad Nacional de Bogotá (la universidad pública más importante de Colombia) por parte del ejército nacional; “¿Qué es la democracia?” (1971) confronta las elecciones presidenciales de 1970, y fue tal vez su película de mayor público, fundamentalmente en los cineclubes de las universidades públicas que bullían en complejas discusiones políticas. (Torres. 2004.) Comprometido con las ideas socialistas de la época, sufrió las consecuencias de la represión, pasando por la cárcel y el exilio; aun así, ayudó a constituir canales de difusión de documentales 
latinoamericanos, especialmente del películas del Tercer cine y del Cine imperfecto, más adelante fue cofundador de la Fundación Nuevo Cine Latinoamericano, participando como miembro de su consejo directivo (Pérez, $r \cdot 1 \uparrow$ ).

Carlos Mayolo, Luis Ospina y Andrés Caicedo pertenecían a un grupo de jóvenes inquietos de la ciudad de Cali, con los cuales se consolida la mitología del Caliwood (Suárez, 2009). Estos jóvenes se reunían en el centro cultural Ciudad Solar, donde la actividad giraba en torno a experimentaciones artísticas e investigaciones estéticas que tenían como eje fundamental la ciudad de Cali donde habitaban. En este espacio se produjeron las primeras películas de Carlos Mayolo y Luis Ospina, quienes convergían además en el Cineclub de Cali y en la revista Ojo al Cine. Sus películas en principio eran adaptaciones de los textos de Andrés Caicedo y luego con reflexiones a través del documental experimental (Suárez, 2009). Así, los primeros años de la década de los 70, fueron dominados por el cine en $16 \mathrm{~mm}$ en blanco y negro, con alto impacto en el cine documental. Igualmente se estrenaron títulos en 35 $\mathrm{mm}$ para las salas de cine con énfasis en los melodramas, en los temas nacionalistas y en la cultura popular.

En 1971 mediante el decreto 879, se aprueba y reglamenta la Ley de Sobreprecio, con casi 30 años de atraso (previamente se había aprobado la Ley 9 de 1942), donde se reconocía el cine como industria de interés nacional. Esta Ley de Sobreprecio indicaba que por cada película extranjera proyectada en las salas de cine, se debía proyectar un cortometraje colombiano, el cual sería financiado con un sobreprecio en la boletería (Acosta, 2009). En 1974 se produjeron 94 cortometrajes con recursos del sobreprecio, por lo que el gobierno debió establecer una guía de calidad para la asignación de los recursos.

El sistema fue un buen laboratorio de experimentación de muchas empresas productoras y realizadores, al permitir que se beneficiaran cineastas como Lisandro Duque, Ciro Durán, Carlos Mayolo y Luis Ospina, entre muchos otros, sirviendo de plataforma de preparación técnica, fortalecimiento de empresas y apoyo a proyectos de las regiones. Asimismo se estableció una cuota de pantalla, para la proyección obligatoria de películas nacionales. La falta de calidad de muchos proyectos, realizados con afán económico o bajo presiones de distribuidores y exhibidores, unida a la corrupción en la asignación de recursos, le creó un estigma de baja calidad a los proyectos financiados por la Ley de Sobreprecio, deshonra en el cine colombiano que perdura hoy día.

En este sentido, con el interés de establecer una industria cinematográfica, de indagar los valores estético-expresivos que permitieran establecer el cine en su nivel superior como obra de arte; pero fundamentalmente como mecanismo para la promoción de la cultura y regulación del engranaje de la cinematografía nacional, se estableció el Decreto 1244 de 1978 a través del cual el Gobierno Nacional exhorto al Instituto Nacional de Radio y Televisión (Inravisión), a la Corporación Financiera Popular y a la Compañía de Informaciones Audiovisuales, a participar en 
la constitución de La Compañía de Fomento Cinematográfico (Focine). Su objetivo era la consolidación y ejecución de políticas sobre la industria cinematográfica, y el recaudo, administración e inversión de los recursos del Fondo (Acosta, 2009).

Inicialmente Focine brindó créditos hasta del $70 \%$ del costo de producción e incluso para la adquisición de equipos y película virgen. Estos recursos eran adquiridos a través del recaudado en taquilla de todas las películas exhibidas, con la exigencia de garantías económicas a las producciones comerciales y como "préstamo especial" para los proyectos considerados valiosos (los cuales realmente dependían de las buenas relaciones de los cineastas).

Se orientaron las fórmulas de producción hacia una cinematografía industrial y burocrática, de una infraestructura opulenta, con recetas imitativas del cine internacional, inadecuadas para los presupuestos disponibles. A pesar de la cantidad de proyectos financiados por Focine, pocas cintas lograron cubrir sus costos de producción y por la misma razón llevaron a la quiebra a productores y realizadores. Estos descalabros de taquilla eran producto de la baja calidad de las películas y el poco interés que generaban en el público, como también, del bloqueo indirecto que provocaba en monopolio la exhibidora Cine Colombia, la cual copaba los canales de distribución y exhibición, indicando los supuestos éxitos de taquilla en Colombia, situación que aún persiste.

Ante el evidente fracaso de la fórmula del préstamo de dinero a cineastas sin experiencia financiera, Focine se inclinó por la producción directa, financiando y produciendo proyectos desde 1984 a 1987, el resultado nuevamente fue un fracaso económico. Tal corrupción generó el despido masivo de altos funcionarios en 1984. Para algunos críticos, como José Luis Zapata (2004), Focine "había sido manoseada, desangrada y prácticamente descuartizada por los políticos, los grupos económicos con intereses en el sector y, quién lo creyera, algunos de los propios cineastas" (Zapata, 2004. p. 53). Igualmente, con el apoyo a la formación cinematográfica, hijos de las ilustres familias consiguieron vacaciones pagas en Europa y EUA para "estudiar producción y realización" u "observar mercados para el cine colombiano" (Ibíd.).

Realizadores como Martha Rodríguez y Jorge Silva siguieron produciendo sus excepcionales documentales realizados fuera de la financiación estatal, lo mismo que autores como Francisco Norden, quien con su magnífica obra "Cóndores no entierran todos los días" (1984) demostraba la madurez del cine nacional; Luis Ospina y Carlos Mayolo realizaron piezas fundamentales en la época como "Pura sangre" (1982), "Carne de tu carne" (1983) o "La mansión de Araucaíma" (1986); Sergio Cabrera rodó con el apoyo de Focine y el ICAIC de Cuba: "Técnicas de Duelo", en 1987, esta película fue relanzada en 1994 con el título de "Águilas no cazan moscas"; Camila Loboguerrero realizó el homenaje a "María Cano" (1990); igualmente, en este periodo se llevó a cabo el rodaje de un magnifico guion de Alexandra Cardona, a manos del director Jaime Osorio con el premiado filme: "Confesión a Laura" 
(1990) e incluso Jairo Pinilla -considerado por algunos como el padre del cine de terror, el suspenso y la ciencia ficción en Colombia- generaron sus más importantes obras durante este periodo de Focine. Es innegable el progreso técnico y narrativo desarrollado durante la época, pues los realizadores y técnicos fueron adquiriendo "oficio", la experiencia continua en los rodajes y la integración de los cineastas en los equipos de producción estimuló el aprendizaje; aun así, las dificultades estéticas y narrativas no fueron completamente resueltas a través de este aprendizaje.

Finalmente, a principios del año 1993, Focine es liquidado; de sus 31 largometrajes solo "Tiempo de Morir" (1985) obtuvo ganancias económicas, mientras las demás dejaron un promedio de pérdida del $80 \%$ de la inversión. La esperanza trazada en un modelo incompleto, politizado y burocrático generó la debacle del oneroso apoyo estatal; de los 36 créditos que se otorgaron en 1978 para la financiación a particulares, 26 se perdieron casi en su totalidad (Revista Semana, 1993). Focine cerró sus puertas finalmente con deudas económicas impagables y con el estéril terreno heredado por el cine nacional.

Después del cierre de Focine, la producción cinematográfica decayó vertiginosamente; los que apostaron a la taquilla perdieron más que sus sueños, el apoyo estatal se redujo a su mínima expresión a través de préstamos financiados por el Instituto de Fomento industrial-IFI, que "ha sido el instrumento financiero estatal encargado de promover la fundación, el ensanche o la fusión de empresas de producción básica" (Garay, s.f.).



Imagen 4. Fotograma de la estrategia del caracol, de Sergio Cabrera (1994). Reproducción de un fotograma en video capturado de DVD original 
Los cineastas acudieron a recursos privados y del exterior, y en algunos casos lograron sobrevivir en la taquilla; se puede mencionar los trabajos de Felipe Aljure, Jorge Alí Triana, Ricardo Coral, Víctor Gaviria, Sergio Cabrera y Ciro Durán. En este pequeño grupo de cineastas, se dieron las apuestas entre la desaparición de Focine y el nacimiento de la Dirección de Cinematografía, dependencia del Ministerio de Cultura.

En 1994, Sergio Cabrera vencía en taquilla a "Parque Jurásico" con "La estrategia del caracol". Desde luego, este éxito de taquilla creó un espejismo sobre la posibilidad de existir sin el apoyo estatal, idea que rápidamente fue demolida por los números. Se estrenaron 47 películas de ficción durante una década, desde el cierre de Focine en 1993 hasta la promulgación de la Ley de cine en el 2003; menos de cinco películas por año, de las cuales muy pocas sobrevivieron a la crítica y a la taquilla.

Entre algunos ejemplos destacados se encuentra "Rodrigo D, No futuro" (1990), ópera prima del director Víctor Gaviria, filme que fue invitado a la Selección Oficial del Festival de Cannes, filme en el que se explora la marginalidad de los jóvenes, la música punk y la muerte en las barriadas de Medellín. Felipe Aljure en 1991, con "La gente de la Universal" hace un retrato inteligente e irónico sobre la idiosincrasia nacional, la burocracia, el rebusque, la corrupción de funcionarios públicos y el valor del asesinato. Existen también dos trabajos que, en apariencia, reunían todos los méritos para esperar un resultado notable: "Edipo alcalde" (1996) e "Ilona llega con la lluvia" (1996), con directores de amplia experiencia como Jorge Alí Triana y Sergio Cabrera, guiones basados en textos de sendos escritores colombianos como Gabriel García Márquez y Álvaro Mutis y un grupo actoral de primera línea. Lamentablemente, el resultado de ambos proyectos no registró los niveles de público esperado, poniendo en cuestión nuevamente las grandes dificultades de la transmutación de una obra literaria a la pieza cinematográfica, y revela además las falencias en los modelos de coproducción internacional.

En 1997, se cerro el Instituto Colombiano de Cultura-Colcultura, entidad encargada de "la elaboración, el desarrollo y la ejecución de los planes de estudio y fomento de las artes y las letras; el cultivo del folclore nacional" (Diario Oficial, 1969). En ese mismo momento, en las duras condiciones de la cultura y el arte se vio con esperanza la aprobación de la Ley de Cultura, lo cual permitió la creación del Ministerio de Cultura. Unos pocos años más adelante, cineastas y empresarios, con el apoyo del Ministerio de Cultura, lograron la aprobación de la Ley 814 del 2003, mejor conocida como Ley de Cine, una norma que ha impulsado la producción audiovisual nacional mediante la creación de estímulos tributarios a quien invierta o done en un proyecto cinematográfico nacional. La Ley creó el Fondo para el Desarrollo Cinematográfico, regido por Proimágenes Colombia, que se nutre de un impuesto a las taquillas de cine (Moncada, 2015). Sus estatutos se encuentran vigentes aun en el 2020 y han permitido en gran medida la nueva cara del cine colombiano contemporáneo. 


\section{CONGLUSIONES}

La cinematografía colombiana y latinoamericana han estado inmersas en el devenir histórico de la cultura mundial, formando parte del proceso de representación contra hegemónico. La dinámica marcada por la represión militar de las dictaduras en todo el continente- encontró respuesta en la mayoría de los movimientos culturales de los años 60,70 y 80, tanto desde las artes plásticas, la literatura, las artes escénicas, la música y lógicamente el cine y el video. A pesar de la gran actividad cultural, los proyectos cinematográficos se vieron limitados por las dificultades económicas, especialmente en los proceso de distribución y exhibición de proyectos que pusieran en tela de juicio el statu quo.

La injerencia norteamericana ha sido otro factor patente en todo el recorrido de la historia política y cultural de América Latina, y obviamente sobre los mecanismos cinematográficos, imponiendo patrones de producción y manteniendo la política del Gran Garrote (Big Stick) sobre toda América. Esta intromisión apoyada en la Doctrina Monroe, evitaba cualquier presencia no americana en el continente, y decidía sobre la "incapacidad" de los propios países para resolver sus conflictos, especialmente cuando por medio de sus decisiones soberanas se veían afectados los intereses norteamericanos. Esta doctrina afectó tremendamente a Colombia en varias ocasiones, entre ellas: el despojo del Departamento de Panamá, convirtiéndolo en un país (casi) anexo a los Estados Unidos, igualmente, a nivel cinematográfico este control imperial prohibió películas como "Garras de oro" que apenas vio la luz hace pocos años atrás.

Desde sus inicios, el principal interés del cine colombiano ha estado en el negocio de la distribución y exhibición, dejando para quijotes la ardua tarea y riesgo de producir y realizar películas. Los distribuidores se han mantenido muy fieles a las "Majors" norteamericanas, en detrimento de las opciones de otros cines, ya sean europeos, latinoamericanos e incluso nacionales. Entre las exhibidoras de mayor peso, Cine Colombia, define el éxito futuro de los proyectos en los procesos de producción de películas colombianas, apoyadas por recursos estatales. En este sentido, el realizador Carlos Zapata sostiene que "El cine independiente o con miradas diferentes no tiene cabida en las salas comerciales, que cada vez se convierten más en parques de diversiones, donde el entretenimiento y la comida rápida priman". (Peláez, 2015, p. 15)

Sin embargo, a lo largo de los años se realizaron acciones para regular la actividad cultural, las cuales fueron fortalecidas a través de la promulgación de la Ley 397 o Ley General de Cultura en 1997, que buscaba la protección del patrimonio, su fomento y financiación, como también la sensibilización a la sociedad frente a estos derechos culturales. El desarrollo de estos derechos fundamentales y el reconocimiento que el Estado colombiano ha implementado, con políticas públicas a lo largo de los años para su fortalecimiento, han incrementado en el reconocimiento 
identitario a través de las prácticas culturales. Y con ello lograr el afianzamiento de valores regionales que buscan aceptar la diversidad local, para fortalecer el modo en que las representaciones se hacen concurrentes en la intención de reivindicar las minorías, rompiendo el excesivo centralismo, (Bogotá como centro) de los beneficios y recursos en pro de la cultura. Evidentemente, esta condición no elimina el EstadoNación, pero restablece la relación geopolítica entre centro y la periferia.

La expansión del cine nacional en la actualidad abarca variedad de miradas sobre la realidad: Al lado de las comedias megataquilleras, como las entregas de "El paseo", se han producido películas de autor cuyo valor artístico fue reconocido internacionalmente, como "Los viajes del viento", "La sirga" y la multipremiada "El abrazo de la serpiente", lo que refleja la pluralidad de géneros de las cintas más reconocidas. Esta diversidad controvierte la percepción común en Colombia, donde muchas personas afirman que el cine colombiano muestra solo violencia y narcotráfico. Aun así, se considera que los conceptos no están fijos, sino por el contrario que viajan y se trasladan entre disciplinas, en el tiempo y entre las comunidades como tal. (Bal \& Marx-MacDonald, 2002, p. 10) "El espacio fílmico abre dentro de la cultura colombiana otra posibilidad de resignificar los acontecimientos que nos identifican; a través de percepciones de los estados propios o ajenos, insertados en temporalidades que se ligan estrechamente a hechos y momentos coyunturales que dan cuenta de los sucesos que como sociedad, se construyen y dan lugares a la significación de posibilidades interpretativas" (Jiménez, 2008, p. 49)".

En este contexto las políticas cinematográficas han establecido herramientas económicas fundamentales como: el Fondo para el Desarrollo Cinematográfico (FDC), los estímulos tributarios para inversionistas y donantes. Estos dineros son distribuidos para la financiación en la cadena de producción de películas, igualmente para la capacitación de profesionales, preservación de material fílmico y exhibición. En este orden de ideas, desde que se instauró la Ley de Cine, la cantidad y calidad de las películas en Colombia han mejorado sus particularidades, iniciando del estancamiento comercial y simbólico hasta llegar hoy día a los principales festivales y reconocimientos mundiales y su mejora en el consumo interno.

En líneas generales, es posible afirmar que, a pesar de las grandes dificultades que ha marcado la producción cinematográfica, siempre se ha encargado de representar su tiempo y sus valores, ha estado vigente la necesidad de interpretar el país, de sensibilizar a través de la imagen a un espectador citadino distante de los conflictos reales, país que requiere espacios simbólicos para exorcizar los demonios de la nación.

Es interesante el auge que ha tomado la investigación sobre cine colombiano en los entornos académicos desde las ciencias sociales, las artes y el mismo cine, para lo cual es recomendable una revisión exhaustiva de artículos de revistas que pueden contrastar con información reciente frente a la revisión exclusiva de libros. Las bases de revistas electrónicas están cada vez más presentes en el entorno investigativo 
frente a las temáticas, que permiten interconectar las ideas para el avance del conocimiento sobre cine colombiano en sus múltiples dimensiones.

\section{REFERENCIAS BIBLIOGRÁFICAS}

Acosta Lara, B. P. (2009). Análisis de las políticas de fomento del cine en Colombia. Monografía de grado Universidad Colegio Mayor de Nuestra Señora Del Rosario Facultad de Ciencia Política y Gobierno. Recuperado de: http://repository.urosario. edu.co/handle/10336/1531

Álvarez, C. (14 junio 1981) Magazín Dominical, El Espectador, Bogotá.

Amado, A. M. (2009). La imagen justa: cine argentino y política, 1980-2007. Buenos Aires: Colihue.

Arboleda Ríos, P. (2003). La presencia de la mujer en el cine colombiano. Bogotá, D.C.: Ministerio de Cultura.

Bal, M., \& Marx-Macdonald, S. (2002). Travelling concepts in the humanities: A rough guide. Toronto: University of Toronto Press.

Bedoya, R. (1995). 100 años de cine en el Perú, Una visión crítica. $2^{\mathrm{a}}$ ed. Lima: Fondo de Desarrollo Editorial Universidad de Lima.

Buñuel, L. (1982). Mi último suspiro. Barcelona: Plaza \& Janes Editores.

Concha Henao, A. (2014). Historia social del cine en Colombia. Tomo I. 1897-1929. Los orígenes. La hegemonía del cine francés e italiano. El incipiente cine nacional. Bogotá: Black Maria Publicaciones.

Duque Isaza, E. P. (1992). La aventura del cine en Medellín. Bogotá: Universidad Nacional de Colombia; El Ancora Editores.

Espinosa, J. G. (1976). Por un cine imperfecto (Vol. 2). Madrid: Castellote.

Garay S, L. J. (s.f.). Colombia: Estructura industrial e internacionalización 1967-1996. [Webpage] Recuperado de: http://www.banrepcultural.org/blaavirtual/economia/ industrilatina/ 058.html

García Márquez, G. (1982). Cien años de soledad. Bogotá: La Oveja Negra.

Jiménez, A. (2008). El cine digital como caballo de Troya. Bogotá: Fundación Gilberto Alzate Avendaño.

Johnson, R., \& Stam, R. (1995). Brazilian cinema. New York: Columbia University Press.

King, J., \& Bello, G. (1994). El carrete mágico: una historia del cine latinoamericano. Bogotá: TM editores.

Laguado, H. (18 de marzo 2001). Días de nostalgia. El Tiempo. Lecturas dominicales. 
Martínez Pardo, H. (1978). Historia del cine colombiano. Bogotá: Librería y Editorial América Latina.

Mérida, P., \& Blanco, P. Cayuela, Smith. (2002). El cine: Historia del cine, técnicas y procesos, actores y directores. Barcelona: Spes.

Moncada Esquivel, R. (15 julio 2013). La ley que hizo florecer el cine colombiano. El País. [Web page]. Recuperando de http://www.elpais.com.co/elpais/cultura/ noticias/ley-hizo-florecer-cine-colombiano

Peláez, P. I. (29 noviembre 2015). ¿Existirá un veto al cine colombiano? El País. Recuperado de http://www.elpais.com.co/elpais/cultura/noticias/existira-vetocine-colombiano:

Pérez Murillo, M. D. (coord.) (2009). La memoria filmada: historia sociopolítica de américa latina a través del cine: la visión desde el norte. Madrid: IEPALA.

Romero, M. (2007). Nuevas guerras, paramilitares e ilegalidad: una trampa difícil de superar. En varios, Parapolítica: la ruta de la expansión paramilitar y los acuerdos políticos. Bogotá: Corporación Nuevo Arco Iris, pp. 449-470.

Salcedo Silva, H. S. (1981). Crónicas del cine colombiano, 1897-1950. Bogotá: C. Valencia Editores

Solanas, F., \& Getino, O. (1970). Toward a third cinema. Cineaste, 1-10.

Suarez, J (2009) Cinembargo Colombia: ensayos críticos sobre cine y cultura. Bogotá: Universidad del Valle.

Torres Tovar, C. A. (2004). Arte en los noventa. Bogotá: Universidad Nacional de Colombia.

Valle Dávila, I. del \& Morettin, E. (2016). Cinema and History in the Americas. IdeAs [Online], ${ }^{\vee} \mid$ Printemps/Été 2016, Online since 26 July 2018

Zavala, L. (2010). La teoría del cine en nuestra américa. Archipiélago: Revista Cultural de Nuestra América, 19 (70), 42-49. 